\title{
Leales y vasallos. Españoles, mestizos e indígenas realistas de Huamanga en la Independencia
}

David Quichua

Recibido: 07-jul-20

Aprobado: 20-oct-20

doi: $10.46476 /$ ra.v1i2.47

\section{Resumen}

El presente artículo estudia los sectores sociales que conformaron el bando realista en Huamanga, sus actividades económicas, razones de su identificación con la administración borbónica y las consecuencias económicas que sufrieron en la Independencia. Mediante la revisión de documentos regionales, nacionales e internacionales proponemos que el bando realista en Huamanga estaba conformado por españoles, mestizos e indígenas de diferentes condiciones económicas y responsabilidades administrativas. Dichos sectores sociales se identificaron y defendieron la bandera realista por conservar sus beneficios económicos, políticos y privilegios que les brindaba la administración virreinal.

Palabras clave: realista, español, indígena, Huamanga, Independencia. 


\section{Abstract}

This paper studies the social sectors that comprised the royalist side in Huamanga, their economic activities, the reasons for which they identified with the Bourbon administration, and the economic consequences they suffered after independence. By reviewing regional, national, and international documents, we propose that the royalist side in Huamanga consisted of Spaniards, mestizos, and indigenous people with varying economic conditions and administrative responsibilities. These social sectors identified with and defended the royalist flag to preserve the economic and political benefits and privileges offered to them by the Viceroyalty's administration.

Keywords: royalist, Spaniard, indigenous, Huamanga, independence.

\section{Resumo}

Este artigo estuda os setores sociais que compunham o lado monarquista em Huamanga, suas atividadeseconômicas, as razões de sua identificação com o governo Bourbon e as consequências econômicas sofridas durante a Independência. Ao revisar os documentos regionais, nacionais e internacionais, propomos que o lado monarquista em Huamanga consistia em espanhóis, mestiços e povos indígenas de diferentes condições econômicas e responsabilidades administrativas. Esses setores sociais identificaram e defenderam a bandeira monarquista por preservar seus benefícios e privilégios econômicos e políticos que a administração do vicereinado lhes oferecia.

Palavras-chave: realístico, espanhol, indígena, Huamanga, Independência. 


\section{Introducción}

Diversas investigaciones sostienen que, durante el proceso de la Independencia, los habitantes de la intendencia de Huamanga tuvieron una participación dividida. Las poblaciones del sur se comprometieron con los ideales de la Independencia (Igue, 2012, pp. 207-228); mientras las poblaciones del norte - Huanta y parte de Ancomantuvieron su identificación con la administración borbónica. Esta explicación dicotómica es inadecuada. La participación de los españoles, criollos, mestizos e indígenas fue compleja: unos apoyaron a la corona, otros levantaron armas a favor de la Independencia, un pequeño sector no tuvo una clara identificación con los grupos en conflicto y también otros tuvieron una participación ambivalente. Cada sector defendió sus proyectos, ideas, acciones y participó de acuerdo con sus intereses.

En el presente artículo analizaremos el papel de los sectores identificados con la corona y explicaremos las siguientes cuestiones: ¿Qué sectores sociales de Huamanga conformaron el bando realista? ¿Cuáles fueron sus actividades económicas? ¿Por qué defendieron a la corona? ¿Cómo fueron afectados con la lucha independentista?

Siguiendo la línea dicotómica, las investigaciones de Pozo (1963), Husson (1992), Bonilla (2001, pp. 149-168) sostienen que las poblaciones del norte de Huamanga conformaron la línea realista y tras la derrota en la batalla de Ayacucho, los iquichanos hicieron frente a la instauración de la administración republicana. Por su parte, Cecilia Méndez, después de una prolongada investigación, trabajo de campo e innovadora propuesta teórica, analiza la participación de los iquichanos en la formación de la república peruana (Méndez, 2014). La presencia de los realistas no se puede reducir específicamente a la parte norte y representarla con la participación de los iquichanos. Más bien, como indica Nuria Sala (1989), carecemos de una investigación que explique por qué diferentes sectores se identificaron y lucharon en el bando realista..$^{-}$

Mediante la revisión de los documentos en el Archivo Regional de Ayacucho (ARAY), Archivo Arzobispal de Ayacucho (AAA), Archivo General de la Nación (AGN), Archivo General de Indias (AGI) y Archivo General de Simancas (AGS) proponemos que los sectores realistas no solo se ubicaron en el norte, sino también en el centro y el sur de la intendencia de Huamanga. Estos fueron conformados

1. La expresión realista es controversial y tuvo una composición heterogénea (Sala, 2014, pp. 213-286). Muchas familias, sectores sociales y personalidades eran realistas absolutistas, liberales o se identificaron con ambas tendencias. Los realistas absolutistas defendieron a los reyes; los realistas liberales, conformados por las autoridades políticas y administrativas, aprobaron y pusieron en marcha la Constitución de 1812, defendieron la autonomía local manteniéndose en sus cargos hasta 1824, e incluso otros retomaron sus cargos tras la Independencia (Sala, 2012, pp. 423-450). 
por españoles, criollos, mestizos e indígenas que venían asumiendo los cargos administrativos, militares y eclesiásticos, así como por familias prósperas, dedicadas a la actividad comercial, hacendaria y minera, como también por grupos medianamente acomodados y pobres. Dichos sectores sociales se identificaron y defendieron la bandera realista para conservar sus beneficios económicos, políticos y privilegios que les brindaba la administración virreinal.

En adelante, determinamos los sectores que conformaron el bando realista, sus actividades económicas y las razones de su identificación con la corona. Y en la última parte, abordaremos los gastos y consecuencias económicas que sufrieron durante la guerra independentista.

\section{Sectores realistas}

La intendencia de Huamanga, ubicada en la vertiente occidental de los Andes sur centrales del virreinato peruano, según el censo de 1791, integraba 135 pueblos, 59 distritos y 7 partidos denominados: Anco, Andahuaylas, Cangallo, Huamanga, Huanta, Lucanas y Parinacochas, donde se concentraban 75.284 indígenas, 29.621 mestizos, 5.378 españoles, 943 pardos, 30 esclavos y 303 habitantes de grupos no definidos, sumando un total de 111.559 habitantes (Rivera, 1977, p. 4). De los cuales, los sectores sociales que se identificaron y conformaron la línea realista fueron un grupo significativo de españoles, mestizos y algunos poblados indígenas. ${ }^{2}$

El mayor número de los españoles se hallaban asentados en Andahuaylas, Parinacochas, Lucanas, Huanta y Huamanga. Los mestizos en Huanta, Parinacochas, Huamanga y Andahuaylas. Por su parte, los indígenas con una población total de 75.284 habitantes, aglutinaba el sector demográfico más significativo y estaban establecidos en Huamanga, Huanta, Lucanas y Cangallo, principalmente. ${ }^{3}$

Hacia 1812, durante el proceso de la guerra independentista, la intendencia de Huamanga continuó conservando administrativamente los siete partidos o subdelegaciones (Imagen 1) con una población de 5.378 españoles, 78.954 indígenas, 29.621 mestizos y 957 pardos y esclavos (Eguiguren, 1912[2013], p. 46).

Desde mediados del siglo XVIII, los diferentes sectores vivían en estrechos vínculos sociales y esto se percibía al interior de los pueblos, las haciendas, los centros mineros, las festividades religiosas y las actividades comerciales. Los libros de bautizos del pueblo de San Antonio de Umaro y San Cristóbal de Vischongo (Vilcas Huamán), que datan de 1786 y 1802, evidencian que los Chuchón, una familia de curacas,

2. Otro sector de españoles, criollos, mestizos e indígenas se identificaron con los ideales de la Independencia y participaron decididamente hasta salir victoriosos en la batalla de Ayacucho.

3. En el año 1791, Huamanga concentraba 20.373 indígenas; Huanta, 16.981; Lucanas, 12.700 y Cangallo, 10.011 indígenas (Rivera, 1977, p. 4). 


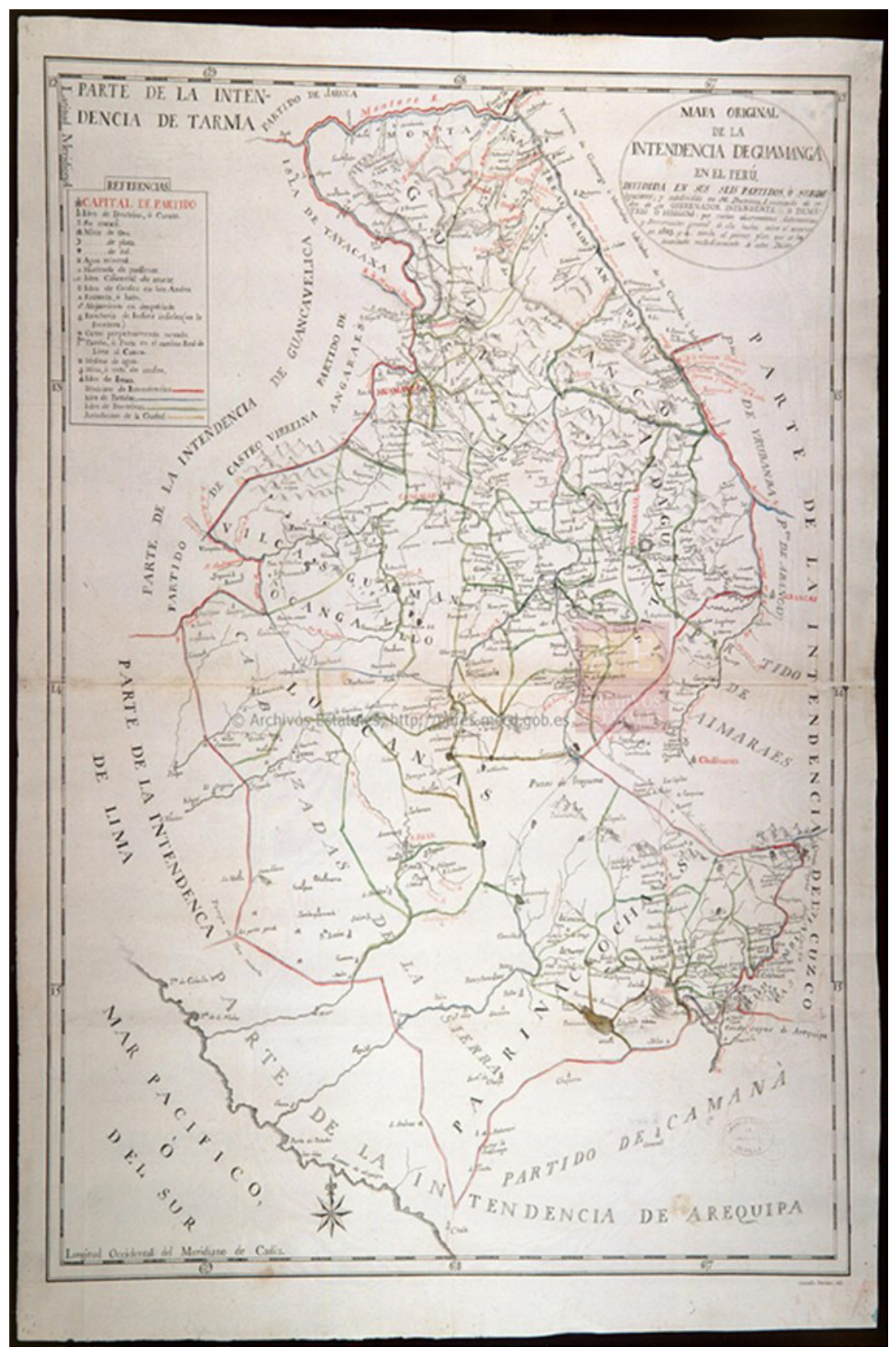

Imagen 1. Mapa de la Intendencia de Huamanga levantada por orden del Gobernador Intendente don Demetrio O'Higgins (1803-1804 [1808]). Archivo General de Indias.

eran padrinos y testigos en los bautizos de los hijos de los españoles, mestizos y los indígenas. Asimismo, tenían por padrinos de bautizos de sus hijos a personalidades de los diferentes sectores. En un pequeño pueblo, los españoles, mestizos e indígenas tenían numerosos ahijados, compadres y comadres. ${ }^{4}$ Las haciendas cocaleras de Huanta y Anco eran usufructuadas y administradas tanto por españoles, como por

4. AAA, Libro de bautizos de Umaro y Vischongo, 1786-1802. 
mestizos, indígenas, militares y eclesiásticos. ${ }^{5}$ Las labores mineras en Lucanas, Vilcas Huamán o Castrovirreyna, permitían la participación y trabajo mancomunado de diversos sectores sociales. En la fiesta de la Señora de Asunta, del pueblo de Talavera (Andahuaylas), los cargos de novenantes, alféreces y capitanes, no tenían distinciones; eran asumidos por españoles, indígenas y zambos, económicamente prósperos e incluso pobres. Los días centrales de la fiesta y la despedida, amenizada con música, cantos y bebidas, eran momentos de confusión y cohabitación homogénea, donde poco o nada importaba las diferencias económicas y sociales. Igualmente, la comercialización de las mercancías, tejidos y la organización de las ferias con la participación de los arrieros, viajeros y las poblaciones de Parinacochas, Lucanas, Andahuaylas y Huamanga, durante las décadas finales del siglo XVIII y comienzos del siglo XIX, eran espacios de integración de los diferentes sectores sociales (Urrutia, 2014, pp. 89-112).

Los estrechos vínculos sociales y culturales desmienten la estratificación jerárquica entre la república de españoles e indígenas. Si existía una jerarquía, era más normativa y una letra muerta en la vida cotidiana. Dichas convivencias permitieron a los españoles, mestizos e indígenas consolidar sus actividades económicas, asumir cargos administrativos y militares más privilegiados e influyentes.

\section{Sus actividades económicas}

Los españoles, mestizos, criollos e indígenas realistas, además de disponer lucros económicos de los cargos administrativos, eclesiásticos y militares que asumían, disfrutaban de mayores ingresos procedentes de sus actividades comerciales, la vida hacendaria y la extracción minera. Por su parte, los indígenas de privilegio, exentos de las mitas mineras, vivían dedicados a las actividades comerciales y agropecuarias.

Si bien las reformas borbónicas, al implantar el comercio libre, perjudicaron la actividad mercantil de los gremios y la producción local de las intendencias (Galdo, 1992), también repotenciaron otros sectores comerciales. Por ejemplo, los tocuyos y bayetas, producidos en los chorrillos o en las casas de los tejedores de los barrios de Huamanga, tuvieron un notable repunte (Urrutia, 2014, pp. 102). De la misma manera, la importación de diversos productos europeos fue generando la bonanza económica de ciertas familias. En la Villa de Huancavelica, una zona periférica al centro de las últimas batallas que sellaron la Independencia del Perú, se ha registrado la mayor presencia de tiendas abarrotadas de licores, ceras y diversos productos de abastos, procedentes de Europa. ${ }^{6}$ En la ciudad de Huamanga, Raymundo Gómez y Vicente Egurrola eran los comerciantes más exitosos y, en sus tiendas, ofrecían las

5. ARAY, Intendencia, Leg. 40, Cuaderno 39, 1800, fs. 1-90.

6. AGN. Ministerio de Hacienda. Sección de contribuciones: libro de matrícula de castas de la provincia de Huancavelica, 1830, fs. 162-162v. 
telas más finas e inasequibles importadas de Europa: pañoletas de seda, varas de algodón, pañuelos estampados de colores, manguillas blancas de gaza, polares de pecho, medias de gaza blanca y varas de casimir negro, productos bienquistos por el pujante y creciente grupo de poder huamanguino. ${ }^{7}$

Por otro lado, los borbones también revitalizaron la actividad minera (Povea, 2014, pp. 36-37). A finales del siglo XVIII y los primeros años del siglo siguiente, los mineros de Huamanga fueron localizando nuevos centros de extracción. En 1805, tras el hallazgo de una nueva veta en las alturas de Castrovirreyna, don Juan Manuel de Orejuela, esperanzado por su pronta recuperación económica expresaba: con la nueva veta «revivirá de alguna manera la antigua opulencia de la casa de los Orejuelas».8 En el asiento minero de Guaychos y Macho Cruz, ubicado en Lucanas, obtuvieron plata. En Cangallo explotaron la mina de oro llamado Paccha. De los socavones el cerro Coyllor y Chicmorara (Tambo) extrajeron plata. Asimismo, extraían salitre en la jurisdicción de Huancarama (Andahuaylas). Y hacia los primeros años del siglo XIX, continuaron explotando la mina de Castrovirreyna (Quichua, 2019, pp. 44).

Del mismo modo, los españoles, mestizos y algunos indígenas afianzaron su poder mediante el control y la producción de las haciendas, ubicadas en los partidos de Andahuaylas, Huanta y Huamanga. En Andahuaylas, las haciendas de Chontaca, Chamana, Catahuacho, Tocsama, Llati, Cormillay, Pomachaca, Cashuacahua, Colpa, Pacchani, Pincos, Carhuayaco, Mosobamba, Chacalla, Socos, Pichus y Sarahuarcay poseían los mejores cañaverales, de las cuales ser obtenía azúcar, chancacas y bebidas que se distribuían en las ciudades y los asientos mineros. Igualmente, la ceja de la selva de Huanta y Anco concentraba los mejores predios cocaleros. Hacia 1800, la quebrada de Buena Lerma, las montañas de Tamboconga, Sanamarca, Pucamarca y la quebrada de Acón, se habían constituido en las zonas de mayor concentración de los hacendados españoles, mestizos, curas y algunos indígenas que usufructuaban las tierras y se dedicaban a la producción de la coca (Cuadro 1). Los 700 hacendados en la ceja de selva de Huanta y Anco (O'Higgins, 1804, pp. 682), y 92 hacendados en el valle de Buena Lerma no disponían del título de propiedad. Para obtener el reconocimiento y posesión de las tierras, presentaron documentos al intendente don Demetrio O'Higgins. Don Pascual Cordero, posesionado en la hacienda real San Juan de Dios, pedía: «con el debido respeto parezco y digo que se sirva usted darme posesión de ella en nombre de su magestad respecto a obtenerla sin documento alguno que me resguarde y asegure el dominio a la finca en consecuencia pondré en andas reales aquella cantidad que resulte pensionado por los peritos tasadores». ${ }^{9}$ El indígena Leonardo Loayza, que disponía de un «cocalito de dos collos de fondo»,

7. ARAY. Juzgado de Primera Instancia, Leg. 01,1825 , fs. $2-2 v$.

8. ARAY. Intendencia, Leg. 31, 1805, f. 5.

9. ARAY, Intendencia, Leg. 40, Cuaderno 39, 1800, fs. 1-90. 
llamado Rosario, tasada en 2 pesos y 7 reales, también solicitaba «posesión de ella en nombre de su magestad» y «el dominio de las fincas». Sin embargo, cuando el intendente determinó la suma de 50 pesos por fanegada, todos rechazaron y decidieron desconocer la autoridad del intendente, y prefirieron hacer predominar su autonomía y entablar un acuerdo con el mismo rey.

Cuadro 1: Haciendas y predios cocales en usufructo, Huanta 1800.

\begin{tabular}{|c|c|c|}
\hline Hacendado & Hacienda cocal & Lugar \\
\hline Pascual Cordero & San Juan de Dios & Quebrada Buena Lerma \\
\hline Antonio Cordero & Calvario & Buena Lerma \\
\hline Casimiro Carreño & San Lorenzo & Buena Lerma \\
\hline Mariano Orcasitas & Cocharcas & Buena Lerma \\
\hline Bernardo Figueroa & La Trinidad & Buena Lerma \\
\hline Atanasio Molina & San Vicente de Sanamarca & Buena Lerma \\
\hline Josef Mariano Calderón & San Miguel de Buenavista & Buena Lerma \\
\hline Antonio Molina & Sta. Gertrudis & Buena Lerma \\
\hline Nicolás Riva & San Agustín de Chuspipata & Buena Lerma \\
\hline Simón Palomino & San Antonio & Buena Lerma \\
\hline Bernardo Figueroa & Concepción de Guaratanca & Montañas de Tamboconga \\
\hline Juan Gualberto Bendezú & San Juan de Dios de Sanamarca & Buena Lerma \\
\hline Martín de Rivera & Santa Isabel & Buena Lerma \\
\hline Norberto Espino & Concepción de Singual & Buena Lerma \\
\hline Mariano Luján & La Concepción de Pintobamba & Buena Lerma \\
\hline Nicolás Anaya & Belimpata (Belén pata) & Buena Lerma \\
\hline Lic. Miguel Calderón & Tierra eriazas & Buena Lerma \\
\hline Gregorio, Pedro y Antonio Arana & Hacienda & Buena Lerma \\
\hline Manuel Cordero & San Lorenzo de Sisipata & Buena Lerma \\
\hline Manuel Pradera & San Mateo de Buen Retiro & Buena Lerma \\
\hline Juan Figueroa & Pintobamba & Buena Lerma \\
\hline Andrés Martel & San Miguel & Buena Lerma \\
\hline $\begin{array}{l}\text { Bernardina Molina y Gabriel } \\
\text { Palomino }\end{array}$ & Trinidad & Buena Lerma \\
\hline Esteban de Alarcón & Sacramento & Buena Lerma \\
\hline Rosa Gonzáles & San Miguel & Buena Lerma \\
\hline Bernarda Molina & San Juan de Sanamarca & Buena Lerma \\
\hline Josef Meneses & Pilcopata & Buena Lerma \\
\hline Anselmo Anaya & Dominio & Buena Lerma \\
\hline Martín de Rivera & Sto. Domingo de Sanamarca & Buena Lerma \\
\hline Manuel Cordero & Sta. Cruz de Buenavista & Buena Lerma \\
\hline Buenaventura Pacheco & Alférez & Quebrada de Pucamarca \\
\hline Pascual Palomino & Sta. María & Tamboconga \\
\hline Presbítero Tadeo Cordero & La Merced & Buena Lerma \\
\hline
\end{tabular}




\begin{tabular}{|c|c|c|}
\hline Hacendado & Hacienda cocal & Lugar \\
\hline Coronel Martín Armendaris & Parayso & Tamboconga \\
\hline Joaquín Ozaeta & Buena Muerte & Tamboconga \\
\hline María Josefa Pacheco & San Vicente & Pucamarca \\
\hline Mariano Luján & Natividad & Buena Lerma \\
\hline Buenaventura Pacheco & San Vicente & Pucamarca \\
\hline Ascencio Loyo & Cedropata & Buena Lerma \\
\hline Pedro Villalta & Nuestra Sra. del Rosario & Buena Lerma \\
\hline Pedro Barbaza & San Pedro de Buenavista & Pucamarca \\
\hline Mariano Mendoza & San Antonio & Buena Lerma \\
\hline Josef Bendezú & San Antonio & Buena Lerma \\
\hline Josef Palomino & Santo Toribio & Buena Lerma \\
\hline Andrés Lobatón & Chacapata & Buena Lerma \\
\hline Esteban Romaní & San Sebastián & Buena Lerma \\
\hline Juan Martel & San Lorenzo & Buena Lerma \\
\hline Alejo Anaya & Sta. Rufina & Buena Lerma \\
\hline Josef M. Calderón & Aypillo & Buena Lerma \\
\hline Pablo Pacheco & Sta. María & Buena Lerma \\
\hline Rafael Oré & Buena Lerma & Buena Lerma \\
\hline Buenaventura Villanueva & San Pedro & Buena Lerma \\
\hline Presbítero Manuel Arana & San Bartolomé & Buena Lerma \\
\hline Luis Lagos & - & Buena Lerma \\
\hline Francisco M. Bellido & San Josef & Buena Lerma \\
\hline Juan Pariona & San Juan Bautista & Sanamarca \\
\hline Bernardo Pariona & San Bernardo & Buena Lerma \\
\hline Ascencio Ruíz & Sta. María & Pucamarca \\
\hline Ascencio Ruíz & San Cristóbal & Pucamarca \\
\hline Petrona Pacheco & San Vicente & Pucamarca \\
\hline Buenaventura Bellido & Rodeo Pampa & Buena Lerma \\
\hline Norberto Bendezú & Espinco & Buena Lerma \\
\hline Nicolás Riva & San Andrés de Chaguachari & Buena Lerma \\
\hline Atanasio Molina & Pintobamba & Buena Lerma \\
\hline Esteban Alarcón & San Mateo & Buena Lerma \\
\hline Josef Meneses & Sta. Teresa & Buena Lerma \\
\hline Manuel Pacheco & Ascensión & Pucamarca \\
\hline Juana Garavito & San Isidro & Buena Lerma \\
\hline Basilio Ruiz & San Cristóbal & Pucamarca \\
\hline Tadeo Meneses & Guaynapata & Buena Lerma \\
\hline Raymundo Meneses & Sta. Bárbara & Buena Lerma \\
\hline Justo Prado & Singualito & Sanamarca \\
\hline Ignacio Gamboa & Ramos pampa & Buena Lerma \\
\hline
\end{tabular}




\begin{tabular}{ccc}
\hline Hacendado & Hacienda cocal & Lugar \\
\hline Marcos Gamboa & San Gerónimo & Buena Lerma \\
Pascual Molina & Jesús María & Buena Lerma \\
Mariano Miranda & Paraguai & Sanamarca \\
Mariano Tapia & San Nicolás & Buena Lerma \\
Clemente Gamboa & Nogal pampa & Buena Lerma \\
Tomás Gamboa & San Miguel & Buena Lerma \\
Ygnacio Martel & Apulima & Buena Lerma \\
Domingo Zamora & Paraiso & Buena Lerma \\
Nicolás Castro & Dolores & Buena Lerma \\
Ambrosio Tito & San Ambrosio & Buena Lerma \\
Mariano Bravo & San Nicolás & Buena Lerma \\
Andrés Farfán & San Antonio & Puca marca \\
María Barrial & La Ladera & Pucamarca \\
Antonio Palomino & Nuestra Sra. del Rosario & Buena Lerma \\
Romualdo Ortega & Chaguachari & Buena Lerma \\
Capitan Cayetano Ganna & San Rafael & Buena Lerma \\
y Diego Cuadros & Buenavista & Sanamarca \\
Justo Prado & &
\end{tabular}

Fuente. Elaboración propia sobre la base de ARAY, Intendencia, Leg. 40, Cuaderno 39, 1800, fs. 1-90.

En el Cercado de Huamanga, hacia 1823, los hacendados prorealistas controlaban y usufructuaban aproximadamente 72 propiedades, entre haciendas, huertas y molinos dedicados a la producción de trigo, alfalfares, frutas y productos de pan llevar (Cuadro 2). Las numerosas haciendas, a pesar de la lucha independentista aún, conservaban su alto valor de tasación. La hacienda de Totora de doña Josefa de la Riva Cosío se hallaba tasada en 16.000 pesos; por la cual pagaba 240 pesos de contribución anual. La hacienda Quicapata y Chilcaccasa, con las 50 cabezas de ganado vacuno, tenía un valor de 10.500 pesos; y don Pedro Martínez, como propietario, contribuía anualmente con la suma de 157 pesos y 4 reales. Asimismo, el molino Canónigo del coronel José Palomino y la hacienda Chaca de Vicente Melchor, se valorizaba en 10.000 pesos anuales; por la cual contribuían con 150 pesos al año. Mientras, la hacienda Totorilla de Rafael Muñoz y Teresa Alcibia eran las menos costosas, que fueron valoradas en 300 pesos; y contribuían anualmente con un monto de 4 pesos y 4 reales. Por otro lado, las huertas eran las menos costosas. La huerta de Alejo Atanay estaba valorizada en 300 pesos y la huerta de don Francisco Méndez en 200 pesos, y por ello contribuía con 3 pesos al año. ${ }^{10}$

10. ARAY, Intendencia, Leg. 40, 1823, fs. 1-10. 
Cuadro 2: Haciendas, molinos y chacras de la ciudad de Huamanga, 1823

\begin{tabular}{|c|c|c|c|}
\hline $\begin{array}{c}\text { Haciendas, molinos y } \\
\text { predios }\end{array}$ & Hacendados & Valor en pesos & $\begin{array}{c}\text { Contribución en pesos } \\
\text { y reales }\end{array}$ \\
\hline $\begin{array}{l}\text { Molino Loreto y tierras } \\
\text { accesorios }\end{array}$ & Mariano Tueros & 6.600 & 99 \\
\hline $\begin{array}{l}\text { Molino Canónigo, } \\
\text { alfalfares y tierras de } \\
\text { yanamilla }\end{array}$ & Cnel. José palomino & 10.000 & 150 \\
\hline Guamanguara & Manuel García & 7.400 & 111 \\
\hline $\begin{array}{c}\text { Santiago, alfalfares y } \\
\text { otras tierras }\end{array}$ & Josefa Palomino & 1.200 & 180 \\
\hline Sta. Elena & Sras. Infanzón & 6.000 & 90 \\
\hline Chaca & Vicente Ruiz & 10.000 & 150 \\
\hline Don Melchor & Sras. Mendieta & 3.000 & 45 \\
\hline Cucho Molino & Diego Balmaceda & 3.000 & 45 \\
\hline Huerta de Huatatas & Ana Hernández & 1.500 & 22.4 \\
\hline Yanama & Pedro José Palomino & 2.500 & 37.4 \\
\hline $\begin{array}{l}\text { Quicapata, Chilcacasa } \\
\text { (más un hato), Paucho } \\
\text { (con } 50 \text { vacunos) }\end{array}$ & Pedro Martínez & 10.500 & 157.4 \\
\hline Nawinpuquio & Casimiro Cervantes & 1.500 & 22.4 \\
\hline Huerta Ñawinpuquio & José de Oré & 600 & 9 \\
\hline Huatata & Pedro Campos & 800 & 12 \\
\hline Riveras de Huatata & N. Zamora & 1.000 & 15 \\
\hline Tierras de Llanopampa & Pedro Castro & 1.100 & 16.4 \\
\hline Chacra Hospital & Tomás García & 400 & 6 \\
\hline Allpaorcona y Llunchi & Gerónimo García & 1.000 & 15 \\
\hline Cabrapata & Pedro Caminada & 3.000 & 45 \\
\hline $\begin{array}{c}\text { Chocan y huerta Aya- } \\
\text { manchi }\end{array}$ & Justo Flores & 3.000 & 45 \\
\hline Huayanpuquio & Juana Eysaguirre & 2.000 & 30 \\
\hline $\begin{array}{c}\text { Tierras de Pampa de } \\
\text { Arco }\end{array}$ & Sras. Ochoa & 1.000 & 15 \\
\hline $\begin{array}{c}\text { Tierras de Pampa de } \\
\text { Arco }\end{array}$ & Márquez de Feria & 2.600 & 39 \\
\hline $\begin{array}{l}\text { La Totora, Las Totori- } \\
\text { llas y otras tierras }\end{array}$ & Josefa de la Riva Cosío & 16.000 & 240 \\
\hline Huatata & Josefa Olano & 500 & 7.4 \\
\hline La Totorilla & Luciano Cueto & 1.000 & 15 \\
\hline Huerta Huatata & Pedro Tello & 1.000 & 15 \\
\hline Totorilla & Ignacio Montoya & 1000 & 15 \\
\hline Totorilla & Jacoba Hernández & 400 & 6 \\
\hline Totorilla & $\begin{array}{l}\text { Parroquia de } \\
\text { La Magdalena }\end{array}$ & 1.300 & 19.4 \\
\hline Totorilla & Rafael Muñoz & 300 & 4.4 \\
\hline Totorilla & Andrés canales & 600 & 9 \\
\hline Totorilla & Teresa Alcibia & 300 & 4.4 \\
\hline Glorieta & Francisco López & 3.000 & 45 \\
\hline
\end{tabular}




\begin{tabular}{|c|c|c|c|}
\hline $\begin{array}{l}\text { Haciendas, molinos y } \\
\text { predios }\end{array}$ & Hacendados & Valor en pesos & $\begin{array}{c}\text { Contribución en pesos } \\
\text { y reales }\end{array}$ \\
\hline Tartaria & Pedro José Palomino & 2.000 & 30 \\
\hline Tartaria & Brianda Cabrera & 1.100 & 16.4 \\
\hline Tartaria & Coronel José palomino & 2.500 & 37.4 \\
\hline Caballitos & María Josefa Palomino & 3.000 & 45 \\
\hline Molinillo & Francisco Hernández & 1.500 & 22.4 \\
\hline Chorrillo (arruinado) & Francisca Bustamante & 1.200 & 18 \\
\hline Molinillo & Isidora García & 1.000 & 15 \\
\hline molinillo & Fermín Robles & 1.000 & 15 \\
\hline Molinillo & Alejo Pérez & 2.200 & 33 \\
\hline San Pedro & Carmen Benítez & 2.500 & 37.4 \\
\hline Buen Retiro & Marcela Palomino & 1.000 & 15 \\
\hline Huerta & Alejo Antay & 300 & 4.4 \\
\hline Huerta & Francisco Méndez & 200 & 3 \\
\hline Chupas & Marques de Feria & 7.000 & 105 \\
\hline Ynyalla & Fam. Calderón & 4.000 & 60 \\
\hline Chupas & Juan Aragonés & 1.500 & 22.4 \\
\hline Chupas & Domingo Joyo & 3.000 & 45 \\
\hline Chupas & Domingo joyo & 1.500 & 22.4 \\
\hline Hahua Pucyo & Ignacio Oré & 400 & 6 \\
\hline Pallca y Huaracco & Santiago Carrasco & 1.000 & 15 \\
\hline Palca & Marcos Romero & 500 & 7.4 \\
\hline Ñahuin Pucyo & Diego Trillo & 800 & 12 \\
\hline UChuy & José Barrientos & 2.000 & 30 \\
\hline Uchuy & Gerónimo Yaranga & 800 & 12 \\
\hline Un pedaso de tierra & Josefa San Juan & 800 & 12 \\
\hline Abril & Los peraltas & 500 & 7.4 \\
\hline Tantaria & $\begin{array}{l}\text { Monasterio } \\
\text { de carmelitas }\end{array}$ & 1.000 & 15 \\
\hline Casa Orco & Josefa Rosa & 2.600 & 39 \\
\hline $\begin{array}{l}\text { Motoy y Hato } \\
\text { Ataguisuar }\end{array}$ & Jacinto Infanzón & 7.000 & 105 \\
\hline Orcohuasi & Francisco López & 2.000 & 30 \\
\hline Pucara & Joaquín León & 3.000 & 45 \\
\hline Umaro & José Ochoa & 600 & 9 \\
\hline Hatun Lucana & Fam. Álvaro & 1.000 & 15 \\
\hline Tancayllo y Gueroba & Gregorio Flores & 4.500 & 67.4 \\
\hline Ychubamba & Fernando Tello & 600 & 9 \\
\hline Yanapiruro & $\begin{array}{l}\text { Bernardino E. } \\
\text { de Cevallos }\end{array}$ & 400 & 6 \\
\hline Total & & 205.100 pesos & 3.076 pesos 4 reales \\
\hline
\end{tabular}

Fuente. Elaboración propia sobre la base de ARAY, Intendencia, Leg. 40, 1823, fs. 1-10. 
Otro de los sectores sobresalientes fue la ganadería, dedicada a la crianza de vacunos, caballares y ovinos. En 1810, tras la muerte del coronel don Francisco García Bedriñana, el inventario de la hacienda Cañaveral de Ninabamba registró la existencia de 7 estancias o hatos situados en el partido de Anco, con un número total de 1.489 vacunos y 31 caballares que se hallaban bajo el cuidado de indígenas pastores y mayordomos (Cuadro 3$).{ }^{11}$

Cuadro 3: Hatos y ganados del coronel Francisco García

\begin{tabular}{|c|c|c|}
\hline Hatos & Tipos de ganado & No. de ganados \\
\hline \multirow{5}{*}{ Llullucha } & Vacas madres & 54 \\
\hline & Toros padres & 14 \\
\hline & Torillos de señal & 2 \\
\hline & Vaquillas de señal & 5 \\
\hline & Orejones y orejonas & 11 \\
\hline \multirow{5}{*}{ Pallca } & Vacas madres & 117 \\
\hline & Toros padres & 65 \\
\hline & Torillos de señal & 4 \\
\hline & Vaquillas de señal & 5 \\
\hline & Orejones y orejonas & 22 \\
\hline \multirow{8}{*}{ Pascia (Paqcha) } & Vacas madres & 116 \\
\hline & Toros padres & 50 \\
\hline & Torillos de señal & 5 \\
\hline & Vaquillas de señal & 4 \\
\hline & Orejones y orejonas & 10 \\
\hline & Yeguas & 24 \\
\hline & Caballos & 6 \\
\hline & Potros & 1 \\
\hline \multirow{5}{*}{ Rayama } & Vacas madres & 107 \\
\hline & Toros padres & 45 \\
\hline & Torillos de señal & 6 \\
\hline & Vaquillas de señal & 10 \\
\hline & Orejones y orejonas & 6 \\
\hline \multirow{5}{*}{ Rumipata } & Vacas madres & 128 \\
\hline & Toros padres & 66 \\
\hline & Torillos de señal & 7 \\
\hline & Vaquillas de señal & 6 \\
\hline & Orejones y orejonas & 7 \\
\hline
\end{tabular}

11. ARAY. Intendencia, Leg. 42, Cuaderno 15, 1810, fs. 1-4. 


\begin{tabular}{ccc}
\hline Hatos & Tipos de ganado & No. de ganados \\
\hline \multirow{3}{*}{ Cuchicancha } & Vacas madres & 57 \\
& Toros padres & 27 \\
& Torillos de señal & 2 \\
& Vaquillas de señal & 3 \\
& Orejones y orejonas & 8 \\
& Vacas madres & 302 \\
\multirow{2}{*}{ Maraycancha } & Toros padres & 106 \\
& Torillos de señal & 35 \\
& Vaquillas de señal & 31 \\
& Orejones y orejonas & 46 \\
7 hatos & Vacunos & 1.489 \\
& Caballares & 31 \\
\hline
\end{tabular}

Fuente. Elaboración propia sobre la base de ARAY. Intendencia, Leg. 42, Cuaderno 15, 1810, fs. $1-4$.

Los indígenas, identificados con la administración virreinal, también conformaban un sector próspero. El intendente don Demetrio O'Higgins, en su recorriendo por las punas del partido de Lucanas (1802) describe:

...en la pampa de Quilcata (actualmente entre Puquio y Cabana), en un temperamento muy rígido por ser toda puna, reside una india nombrada Inés Capcha Huamaní, de edad al parecer de 90 años, afamada de rica, como que posee más de 20,000 cabezas de ganado ovejuno, un número de cabezas de caballar y vacuno, y 20, 000 carneros de la tierra (llamas y alpacas). ${ }^{12}$

La preponderancia de la ganadería indígena también sobresalió en la meseta de Parinacochas, en las extensas planicies de Qaracha (Huancasancos) y las alturas de las doctrinas de Soras y Vilcas Huamán.

En la ciudad de Huamanga, antes de la incursión de la rebelión de los hermanos Angulo en 1814, el indígena Julio Santos Casani había fundado una iglesia. Santiago Castro era un indígena comerciante que pagaba un gravamen de 50 pesos al Convento de Santo Domingo. En las quebradas de Lerma, Tamboconga y Acón, muchos indígenas poseían tierras cocaleras, dirigían su distribución y comercialización (Quichua, 2017, pp. 152).

Por otro lado, los indígenas de nobleza, conformados por los caciques y alcaldes, vivían de sus sueldos, actividades comerciales, ganaderas y agrícolas. El indio principal y alcalde de campo del pueblo de Totos, don Dámaso Sucso, como también, el regidor e indio principal de Chuschi, don Diego Huamán, en

12. Monografía de la provincia de Parinacochas, T. I, 1950, p. 201. 
1810 disponían de tierras y estancias de ganados. ${ }^{13}$ Igualmente, los indígenas privilegiados conformados por «los indios chasquis y puentes» vivían en las doctrinas de Cayara, Huando (Huancasancos), Paras, Chacamarca, Ocros, Chumbes y Vischongo. Como chasquis, tenían la obligación de transportar los correos en el tramo Huamanga-Vilcas Huamán y al ser indios puentes renovaban anualmente el puente de Uranmarca. De esa manera, no participaban en las mitas y se dedicaban a las actividades agrícolas, ganaderas, artesanales, entre otros.

Los hacendados, mineros, comerciantes y ganaderos de los diferentes sectores sociales, defendieron al gobierno español para no perder sus ingresos y confiaban en la seguridad y protección que les podría brindar. Asimismo, los indígenas privilegiados se identificaron con la administración borbónica con el afán de hacer prevalecer sus exenciones.

\section{Las razones de su realismo}

La identificación con la administración virreinal tuvo múltiples razones y cada sector social —españoles, mestizos e indígenas - tuvo sus propias motivaciones.

Los hacendados de la intendencia de Huamanga y Andahuaylas defendieron a la administración virreinal porque las reformas borbónicas, desde mediados del siglo XVIII, promovieron la producción hacendaria y experimentaron un crecimiento económico. Las 72 haciendas ubicadas en la ciudad de Huamanga y sus alrededores sumaban un valor de 205.100 pesos aproximadamente, un monto altamente significativo para la época. Los propietarios se beneficiaban con la comercialización de las cosechas y la renta de sus tierras. El Marqués de Feria y Valdelirios, en 1801 rentó la hacienda Chincheros, Llocclla y Venscha por un lapso de un lustro a don José Lagos a un precio de 2.000 pesos anuales. ${ }^{14}$ En 1805, de la hacienda Chincheros obtuvieron 176 fanegas de cebada y 80 fanegas de trigo; de Llocclla, cosecharon 12 fanegas de papa, 20 fanegas de maíz de primera calidad, 1 fanega de maíz de baja calidad, 4 fanegas y $1 / 2$ de cebada; y de Venscha, 21 fanegas de cebada y 3 fanegas de maíz. En total, de las tres haciendas obtuvieron 325 1/2 fanegas de productos. ${ }^{15}$ Para los grupos de poder económico, el inicio de la lucha independentista hacía peligrar su riqueza, pero a pesar de ello, consideraron un problema efímero que la administración española lograría derrotar como a la rebelión de Túpac Amaru II y mantener el crecimiento económico. ${ }^{16}$

13. AGI. Lima, 74, $\mathrm{N}^{\circ} 67,1810$, f. 19.

14. El contrato indicaba que la entrega del monto referido era por tres años forzosos y dos años voluntarios.

15. ARAY. Intendencia, Leg. 37, 1801-1805, fs. 4-4v.

16. En 1780, a pocos días de iniciada la rebelión de Túpac Amaru II, el cabildo de Huamanga respondió inmediatamente a la carta de José Antonio de Arreche y con el objetivo de derrotar el levantamiento 
El apoyo de los hacendados españoles, criollos, militares, eclesiásticos e indígenas, que usufructuaban las tierras cocaleras de Huanta y el norte de Anco, fue por el amparo especial que recibieron del rey. Como enfaticé líneas atrás, los referidos hacendados inicialmente rechazaron a la administración borbónica, puesto que dichas autoridades, encabezadas por el intendente Demetrio O'Higgins, al pretender obtener mayores ganancias en beneficio de la corona, determinaron vender dichas tierras a 50 pesos la fanega. Los hacendados consideraron que las referidas tierras fueron convertidas en cultivables a costa de mucho trabajo e inversión y era injusto pagarla. En 1813, los diputados por Huamanga, don Pedro José Tello y Martín José Mujica fueron enviados a España y al asistir a las legislaturas ordinarias de 1814 expusieron los problemas por las tierras cocaleras y solicitaron que las autoridades resuelvan con urgencia (Sala, 2014, pp. 254-216). ${ }^{17}$ Desafortunadamente, las autoridades liberales no resolvieron sus pedidos y recién dos años después fue solucionado por el monarca. El rey Fernando VII en 1816 concedió una: «exención de derechos por diez años a los descubridores y cultivadores de los terrenos de las expresadas montañas a los quales prestarán los subdelegados y justicias los auxilios con arreglos a las leyes» (Méndez, 2014, pp. 131). Mediante este amparo, los hacendados restablecieron su identificación con la monarquía, incrementaron el cultivo de la coca y su comercialización garantizó altos ingresos.

De la misma manera, los hacendados defendieron a la monarquía porque las autoridades del cabildo de Huamanga, durante los años más difíciles de la guerra independentista, mantuvieron a la coca exenta de contribuciones y se constituyó en uno de los productos más rentables. En 1818, las autoridades del cabildo de Huamanga, al establecer impuestos al tabaco, aguardiente, aceite, ají, frijoles, entre otros productos, dejaron de lado a la coca. Dice: «Se reservó por esta junta pensionar la coca del partido de Guanta de donde se extrae [y] se niegan sus vecinos a qualquiera otra determinación». ${ }^{18}$ Con este respaldo, la coca llegó a comercializarse en las regiones más distantes del virreinato.

Las autoridades del cabildo no establecieron el impuesto a la coca porque muchos de ellos, sus familiares y amigos usufructuaban dichas tierras y se beneficiaban con la comercialización de la coca. José Palomino era dueño de la hacienda Canónigo, los alfalfares y tierras de Yanamilla; además, era coronel de las fuerzas realistas. Don Gaspar Carrillo de Albornoz Vega Munive exhibía el título de «Marqués de Feria y Valdelirios», disfrutaba de la producción de los fundos más fértiles, asumía

enviaron dinero, armas y hombres. De Andahuaylas mandaron 900 hombres, de Huanta 82 y en Huamanga para contrarrestar cualquier levantamiento prepararon 200 hombres.

17. También solicitaron la restauración de los repartimientos forzosos, aumento del número de prebendas a la catedral, la incorporación de los indígenas en las corporaciones municipales, disminución de réditos de los censos consignativos del 5\% al 3\% y la rebaja de las alcabalas al 4\% (Sala, 2014).

18. ARAY. Libro de actas del cabildo de Huamanga desde 1817-1822, s/f. 
el cargo de brigadier y general del ejército español. Asimismo, el presbítero Tadeo Cordero usufructuaba en la ceja de selva la hacienda cocal La Merced y; Don Martín Armendáriz, además de desenvolverse como coronel de las fuerzas reales, era dueño de la hacienda cocal Paraíso, ubicada en la selva de Huanta, la cual alquilaba al teniente de milicia, Joaquín Ozaeta.

El favoritismo del cabildo creó críticas de otros sectores que venían cumpliendo con las contribuciones. El cura de Chincheros don Manuel Renteros, el 10 de diciembre de 1818, hizo presente sus reproches y sostenía que mientras «la pleve infeliz» cumple con las diferentes tributaciones para salvaguardar a las fuerzas realistas, los del «partido de Guanta no contribuye hasta ahora con ninguna razón y teniendo la coca que se expende en todo el vireynato». ${ }^{19}$ A pesar de las críticas, la coca se mantuvo libre de impuestos y los sectores beneficiados no solo brindaron su apoyo a la administración virreinal por las exacciones referidas, sino también porque las movilizaciones independentistas fueron estableciendo cupos, robos, apropiación de ganados y acémilas, perjudicando la producción, distribución, comercialización de la coca y demás productos (Méndez, 2014, pp. 132).

La situación se hizo más perniciosa, pues la guerra independentista la ganaron los patriotas. A seis días de la batalla de Ayacucho, por imposición de Sucre, los pueblos de Huanta - por su apoyo brindado a los realistas y ataques ocasionados frente a las fuerzas patriotas - pagarían la suma de 50 mil pesos. Del mismo modo, en febrero de 1825, los curas del obispado de Huamanga pagarían 20 mil pesos por encabezar y motivar a los indígenas "para que robasen los equipajes y matasen esos enfermos del ejército patriota» (Méndez, 2014, pp. 133). Definitivamente, el establecimiento de la República de Perú fue muy crítico para las poblaciones de Huanta y motivó un levantamiento en nombre de la monarquía. En palabras de José Antonio Navala Huachaca, líder de los iquichanos, el levantamiento fue por los robos, abusos, desórdenes y elevadas contribuciones que venían cobrando los militares de la naciente república ${ }^{20 .}$

La rebelión de los iquichanos, denominada como el primer levantamiento campesino de la República (Méndez, 2014, pp. 77-104), es uno de los acontecimientos que ha motivado varias investigaciones $y$, sobre las razones de su realismo, sostienen que fue por la caída del comercio de la coca, los robos y altos impuestos que establecieron las autoridades republicanas (Husson, 1992). Además de las referidas causas, el problema de fondo que motivó el levantamiento de los indígenas, españoles, mestizos y eclesiásticos fue el control y usufructo de las tierras cocaleras. ${ }^{21}$

19. ARAY. Libro de actas del cabildo de Huamanga desde 1817-1822, s/f.

20. ARAY, Juzgado de $1^{\text {a }}$ Instancia, Causas Criminales, 1826. Véase: (Bonilla, 2001, pág. 155).

21. Además, si bien la investigación de Cecilia Méndez analiza la participación decidida de los iquichanos en la formación de república peruana, es necesario tomar en cuenta el asunto de la tierra, debido 
Aligual que en Huanta, en las provincias de Huamanga, Andahuaylasy Parinacochas las disputas por el control de los predios, a fines de la administración virreinal y los primeros años de la vida republicana, siguieron siendo asuntos contenciosos. En Parinacochas, los indígenas del ayllu Anansaya y Urinsaya posesionaron las tierras realengas; y en Vilcas Huamán muchos indígenas litigaron con la expansión de las haciendas.

De igual manera, un sector de los indígenas defendió a la administración virreinal porque algunos funcionarios encaminaron cambios significativos en los pueblos: promovieron la educación, mejoraron la salud, priorizaron la ornamentación y encarcelaron a los abigeos. Esto se constata con la declaración de don Cosme Echevarría, quien al desenvolverse en el cargo de Subdelegado de la provincia de Vilcas Huamán sobresalió por las reformas que estableció en beneficio de los indígenas. Un documento de 1811 refiere:

para perpetuo honor de el que suplica su compostura de caminos, la reedificación a sus expensas de las casas de cabildo y cárceles de la capital y de otros pueblos; la traslación viva a costa suya del fluido vacuna en brazos de dos niños, para que el vecindario disfrutara de este celestial preservativo; la erección de una escuela de primeras letras en Cangallo que paga anualmente de su propio peculio con 220 pesos, la erogación continua de medicinas y socorros al vecindario pobre y su dedicación al templo de la cabecera del partido donde elevó un Altar. ${ }^{22}$

La vacuna que hace referencia el documento era la antivariólica, que desde 1805 se fue difundiendo en el virreinato peruano (García, 2003, pp. 41-50) y Cangallo, al nivel de la intendencia de Huamanga fue la primera provincia que dispuso de dicha tecnología. Igualmente, la construcción y funcionamiento de una escuela se constituyó en una de las obras significativas de don Cosme Echevarría. Mediante estos cambios, el subdelegado gozó de una representatividad en los pueblos, que fue constatada y reafirmada unánimemente por los españoles y mestizos que habitaban en los pueblos de Vilcas Huamán y principalmente por los caciques. Sin embargo, vale aclarar que las reformas de Cosme Echevarría crearon incomodidades en otros sectores. Por ejemplo, el subdelegado terminó siendo odiado por los abigeos.

Asimismo, algunos grupos de los indígenas privilegiados mantuvieron su identificación conlacorona, debidoa quelas autoridades delvirreinato determinaron que dichos indígenas continúen desenvolviéndose en sus labores especializadas. Tal es así, los indígenas de Vischongo, que no participaban en las mitas mineras y a cambio de ello tenían la función de renovar el puente de Uranmarca en el curso del

que durante los primeros años de la naciente república el problema del control de las tierras cocaleras siguió vigente y el apoyo o rechazo que brindaron los iquichanos a los caudillos dependió de las legislaciones que fueron estableciendo sobre la tierra.

22. AGI. Lima, 74, $\mathrm{N}^{\circ} 67,1811$, s/f. 
río Pampas, conservaron dichas labores y en 1813 solicitaron al virrey un amparo para seguir con el privilegio. ${ }^{23}$ El pedido fue admitido y durante los últimos años de la administración virreinal, a pesar que la constitución de 1812 prohibió todo tipo de tributación indígena, los vischonguinos siguieron renovando el puente. Con la restauración de la monarquía en 1814, los vischonguinos mantuvieron sus privilegios y facilitaron las actividades administrativas, la distribución de los correos, la movilización de las tropas e hizo posible la continuidad de la administración virreinal, hasta la batalla de Ayacucho en $1824 .^{24}$

Los diferentes sectores identificados con la corona y la intendencia de Huamanga, al mantenerse bajo la administración virreinal hasta las últimas consecuencias de la prolongada guerra independentista, conllevaron todo el peso de la contienda, abastecieron la guerra y sufrieron los mayores perjuicios.

\section{El precio del realismo}

Los españoles, mestizos e indígenas que defendieron a la Corona española y apoyaron a las fuerzas realistas sufrieron los mayores daños de la guerra. Algunos funcionarios fueron apedreados, otros ejecutados y los grupos de poder económico sufrieron saqueos.

El incremento del impuesto de alcabala al 6\% y el aguardiente al 12.5\% desde 1776, generaron rechazos de los comerciantes y los cobradores terminaron atacados. El cobrador de alcabalas, don Gerónimo Rojas, durante su usual transcurso del pueblo de Pacapausa al anexo de Opahuacho (Parinacochas), fue apedreado en 1805 por los hermanos José y Rudecindo Castañeda. Según el informe del agraviado, le tendieron una emboscada, a punta de pedradas le hizo caer del caballo y le arrebataron el padrón de la alcabala (Quichua, 2019, p. 58).

Durante la rebelión cusqueña de 1814, el grupo dirigido por el argentino Manuel Hurtado de Mendoza, el cura José Gabriel Béjar y el criollo Mariano Angulo, al controlar la ciudad de Huamanga, ocasionaron una turbación social y un desequilibrio económico (Rojas, 2016, pp. 363-384). ${ }^{25}$ Las autoridades y algunas familias acomodados optaron por retirarse de la ciudad $y$, aquellos que hicieron

23. Por el contrario, los indígenas privilegiados de Huamanga y otras doctrinas que no tenían la función de participar en las mitas y cumplir con las tributaciones, con la intensificación de las reformas borbónicas desde las últimas décadas del siglo XVIII fueron perdiendo dichos privilegios y al ser empadronados bajo la condición de indígenas comunes, cumplieron con las tributaciones. Esto generó mayores incomodidades, rechazaron rotundamente a la administración borbónica y posteriormente levantaron armas a favor de la independencia. Véase: (Quichua, 2019).

24. La práctica del chaka tikray (renovación del puente) se mantuvo hasta a mediados del siglo XX.

25. Aunque no es objetivo de este artículo, es importante aclarar que la rebelión de 1814 tuvo un significativo apoyo por parte de los comerciantes, los gremios y los indígenas afectados por las reformas borbónicas. Véase: (Quichua, 2019, pp. 25-53). 
frente y continuaron en sus cargos terminaron ejecutados, entre ellos, el capitán Vicente Moya, el intendente Tincopa y el subdelegado de Vilcas Huamán don Cosme Echevarría (Pereyra, 2016, pp. 339-361).

Sobre las nefastas consecuencias económicas, el hacendado y diezmero don Francisco Flores describía la crítica situación con estas palabras: «en la revolución de 1814 empezaron mis ruinas»; pues la rebelión desarticuló el comercio de diversos productos artesanales. Empezaron a pedir, forzosamente, a los hacendados alfalfares, fanegas de cebada, cargas de paja para la manutención de los caballos, vacunos para la alimentación de las tropas, mulas y caballos para el transporte.

Las casas de los vecinos principales fueron saqueadas, los granos vendidos a un bajo precio y los diezmos se hicieron incobrables. Don Pedro Caminada, comerciante, diezmero y hacendado, se quejaba: «en la insurrección de 1814 los insurgentes saquearon mi casa por ser yo europeo sin dejarme ni colchón en que dormir y degollaron más de 100 cabezas de ganado vacuno en una corta hacienda que poseo...». ${ }^{26}$

Del mismo modo, los morochucos, que apoyaron a la insurrección cuzqueña, a los ganaderos y hacendados que se mantuvieron fieles a la Corona, les causaron los mayores estragos. Don José María Palomino testificó:

...en la insurrección de $1814 \mathrm{mi}$ hacienda de vacas nombrada Sachabamba, situada en partido de Cangallo fue el centro de las correrías de los insurgentes y morochucos, quienes por castigar mi inequívoca fidelidad al señor nuestro se robaron casi todo el ganado vacuno y caballar (...) de manera que de centenares de vacas y caballada que en ella tenía, apenas recogí después cincuenta y tantas cabezas de ambas especies y las casas todas incendiadas... ${ }^{27}$

La ruta que atravesaron los insurgentes había quedado devastada, y esta situación se agravó aún más.

A pesar de la derrota de una de las alas de la rebelión cusqueña de 1814, en los campos de Huamanguilla, Macachacra y en las cercanías de Huanta, entre el 25 de setiembre y el 2 de octubre (Hamnett, 2011, pp. 191-192), las acciones rebeldes continuaron (Ruiz, 1924, p. 101) y perjudicaron las actividades comerciales de las familias potentadas de Huamanga (Zapata, Antonio, Pereyra Nelson y Rolando Rojas, 2010,pp. 122). La exportación delos productos dela región, como las badanas y los tocuyos destinados al centro minero de Cerro de Pasco, quedaron frustradas. La comercialización del aguardiente - que se importaba desde Moquegua y otras haciendas de la costa central y sureña - también fue interrumpida por los

26 ARAY. Intendencia, Leg. 42, Cuaderno 58, 1814, f. 29.

27 Ibíd., 1814, f. 78. 
constantes ataques de los rebeldes y por la falta de las acémilas que fueron tomadas para las revueltas. De tal manera que la mayoría de comerciantes se hallaba en crisis. El 28 de febrero de 1817, el comerciante Bernardino Fernández informaba que se hallaba en un lastimoso estado de quiebra y pedía a sus acreedores «se sirva concederle el tiempo que permite la ley» para pagar sus deudas. ${ }^{28}$ En la ciudad de Huamanga, debía a 17 familias la suma total de 1.075 pesos (véase: cuadro 4).

Cuadro 4: Deuda de Bernardino Fernández, 1817.

\begin{tabular}{cc}
\hline Prestamistas & Sumas en pesos \\
\hline Don José María & 200 \\
Don Juan de Dios Muñoz & 180 \\
Don Juan Alarcón & 130 \\
Don Clemente Mendieta & 100 \\
Don Mariano Meneses & 90 \\
Don Teodoro Cabrera & 70 \\
Don Rafael Carrera & 50 \\
Don Pedro José Avilés & 40 \\
Don Juan Cantor & 30 \\
Doña Eusebia Guillén & 40 \\
Doña María Godoy & 30 \\
Don Francisco Rua & 20 \\
Don Agustín Barrera & 40 \\
Doña C. Castro & 22 \\
Don José Flores & 10 \\
Don Egidio Huamán & 8 \\
Don Atanasio Huamán & 15 \\
\hline Total & 1.075 pesos \\
\hline
\end{tabular}

Fuente. ARAY. Intendencia, Leg. 48, 1817, f. 1.

La incursión de los patriotas y la desarticulación de la economía huamanguina indujeron a los sectores potentados adherirse con mayor razón al realismo porque consideraron estos acontecimientos como pasajeros y creían que con el apoyo a la corona se restablecería el orden.

\section{Aportes económicos}

Las ciudades de Huamanga, Huanta, Cangallo, entre otras, solo en ocasiones pasaron al control de las fuerzas independentistas y, por el contrario, la intendencia en general se mantuvo bajo la administración virreinal hasta las últimas etapas de la guerra y constituyó un bastión económico para los bandos en conflictos, siendo esencialmente de las tropas de la corona.

28. ARAY. Intendencia, Leg. 48,1817, f. 1 . 
Años después de la derrota de la rebelión de Túpac Amaru II, en las capitales provinciales de Huamanga se establecieron las milicias con el afán de mantener la seguridad interna y eliminar cualquier intento separatista. En 1788, el Regimiento de Caballería de Milicias de Cangallo (Vilcas Huamán) estaba compuesto por un coronel, un teniente coronel, un sargento mayor, dos ayudantes, cuatro portaestandartes, diez capitanes, doce tenientes y la misma cantidad de alféreces. ${ }^{29}$ El Regimiento de Milicias Provinciales Urbanas de Caballería de Huanta en 1798 se hallaba dirigido por el coronel don Felipe Días de la Torre, el teniente coronel don Domingo Pérez, el sargento mayor don Antonio Beramendi, cuatro capitanes, un ayudante mayor, siete tenientes, siete alféreces, nueve sargentos y tres cadetes. ${ }^{30}$ Asimismo, la milicia «Leales Voluntarios de Guamanga» en agosto de 1820 estaba dirigido por el intendente Francisco José de Recabaren y conformado por diez capitanes, once tenientes, diez subtenientes y ocho cadetes. Dichas milicias se mantuvieron mediante la contribución de los diferentes sectores sociales, colaboración de los grupos de poder económico, las instituciones religiosas y administrativas. Por ejemplo, las autoridades del cabildo de Huamanga en 1820, para la manutención de los soldados, entregaron la suma de 522 pesos. ${ }^{31}$

Sin embargo, las milicias se caracterizaron por su debilidad y durante el arribo de las rebeliones no pudieron detener y salvaguardar a la ciudad de Huamanga. Un ala de la rebelión cuzqueña de 1814 tomó Huamanga con relativa facilidad y las autoridades huyeron (Pereyra, 2016). Igualmente, en el momento de la llegada de las fuerzas de Álvarez de Arenales, el intendente Francisco Recabaren y las tropas decidieron huir, dejando el cargo al teniente asesor don Juan José Eguiluz. El oficio de 28 de octubre de 1820 dice: «Tomadas todas las medidas posibles no encuentro arbitrio para defender esta plaza del enemigo que se nos acerca y mucho menos permite un empleo entregarla con las armas y poca tropa que guarnece, así que he resuelto retirarme con ella y que usted queda en el mando». ${ }^{32}$ Frente al abandono, el cabildo decidió dejar el ingreso libre a las fuerzas de Arenales, cumplieron con todos los requerimientos logísticos y económicos durante su estadía en Huamanga.

Paradójicamente, al retirarse las fuerzas de Arenales, la ciudad de Huamanga fue inmediatamente retomada por las tropas realistas del general Mariano Ricafort y posteriormente, José Carratalá encaminó la más brutal persecución a los rebeldes $\mathrm{y}$ en ese contexto los habitantes de Huamanga brindaron un decidido aporte económico. El 4 de diciembre de 1820, Carratalá ordenó al capitán Joaquín Rubin pedir préstamos con un interés de un 5\% a los grupos de poder de Huamanga;

29. AGS. Milicias de Cangallo, Empleo, Leg. 7119, 1788, f. 179.

30. AGS. Milicias de Caballería de Huanta, Leg. 7286, 17, 1798.

31. ARAY. Libro de actas del cabildo de Huamanga desde 1817-1822, s/f.

32. ARAY. Libro de actas del cabildo de Huamanga desde 1817-1822, s/f. 
pues «las tropas carecían de todo auxilio y era importante y justo socorrerla». ${ }^{33}$ Con el objetivo de obtener la suma de 100,000 pesos, los encargados elaboraron el padrón de los vecinos pudientes: el obispo y el clero entregarían la suma de 20,000 pesos, el Cabildo secular 5,500 pesos, los comerciantes la suma de 22,000 pesos, los hacendados 12,600 pesos y los demás vecinos 6,000 pesos. En total, sumó 60,600 pesos. Asimismo, los vecinos ausentes brindarían la suma de 2,000 pesos, los hacendados de Andahuaylas 11,500 pesos y los de Cangallo 2,000 pesos, que adicionarían un monto de 15,500 pesos. De tal manera, el grupo de poder económico y político de Huamanga y sus provincias, debía entregar la suma total de 76,100 pesos. Desafortunadamente, no alcanzó los 100,000 pesos requeridos. ${ }^{34}$

Las principales familias, al recibir la notificación y los montos determinados pidieron rebajas. Expresaron la difícil situación económica que había ocasionado la rebelión de 1814, la decadencia de la actividad comercial y la imposibilidad del cobro de los diezmos por las insurgencias. Melchor Arespi se negó a entregar los 1,000 pesos asignados, indicando que las insurgencias no le permitían transportar y comercializar más de 300 tocuyos a Cerro de Pasco. Doña Paula Orosco, esposa del subdelegado interino y cobrador de diezmos de Parinacochas don Ignacio Montoya, indicó que no disponía del monto asignado; porque su esposo no había podido cobrar los diezmos «por lo alborotado que se hallan las gentes». ${ }^{35}$ Asimismo, el indígena Santiago Castro se negó a pagar los 1,000 pesos, por hallarse en bancarrota y por la imposibilidad de continuar su actividad comercial por las convulsiones. Otros se hallaban cargados de deudas y paralizados. Don Fermín Felices se justificó con estas expresiones:

Yo fui señor en tiempos pasados viajero, más desde ahora años en que sufrí un robo en el pueblo de Pausa, quedé asentado sin poder levantar la cabeza, mi edad que es octogenaria no me permite ya trabajo alguno. Tengo varios acreedores que me toleran por insolvencia, sin tener de donde echar mano, mendigo en sustento y sobrevivo a expensas de la caridad y aunque poseo una casita en la calle Santa Teresa esta se halla gravada con un censo a favor del monasterio de Santa Clara que estoy también debiendo los réditos. ${ }^{36}$

En una situación difícil, solo se comprometieron a brindar la mitad del monto indicado; y otros a hacer donaciones voluntarias de acuerdo a sus posibilidades. De tal manera, trascurridas las 48 horas, los realistas obtuvieron 22,750 pesos y continuaron con la cobranza respectiva (Cuadro 5).

33. ARAY. Intendencia, Leg. 42, Cuaderno 58, 1820, f. 1.

34. Ibíd., 1820, fs. 2-4.

35. Ibíd., 1820, fs. 18-30.

36. Ibíd. 1820, f. 42. 
Cuadro 5: Relación de los prestamistas y los montos, 1820.

\begin{tabular}{cc}
\hline Prestamistas & Monto en pesos \\
\hline Gregorio Ulloa (por parte de la Iglesia) & 1.000 \\
Gregorio Ulloa & 1.000 \\
Canónigo Penitenciario & 1.000 \\
Fernando Fernández (Regidor) & 3.000 \\
José Vicente de Egurrola & 1.000 \\
Mariano Soto (cura de Vizchongo) & 1.000 \\
Luis Aristizabal (prebendado) & 500 \\
Diego Balmaceda (Regidor) & 500 \\
Miguel de Irriarte & 5.000 \\
Josefa Palomino & 1.000 \\
José Soto & 500 \\
Pedro Bendezú & 500 \\
Dean de la Iglesia & 500 \\
José León (Prebendado) & 200 \\
Marcelo Castro & 500 \\
Juan de Dios Ronceros (Presbítero) & 150 \\
Simón Tueros & 1.000 \\
Francisca Larria (Larrea) & 300 \\
Melchor Quispe & 500 \\
Santiago Castro & 500 \\
Francisco García y Espinoza & 600 \\
Hermenegilda Cárdenas & 1.000 \\
Juan Frías & 800 \\
Cura de Querobamba (donativo) & 300 \\
Francisco Hernández (donativo) & 300 \\
María Alcibia (donativo) & 100 \\
Total & 22.750 \\
\hline & \\
\hline &
\end{tabular}

Fuente. ARAY. Intendencia, Leg. 42, Cuaderno 58, 1820, f. 1.

Como se puede observar en el cuadro anterior, la recaudación de los 22,750 pesos, se logró gracias a la mayoría de los aportantes, los montos más significativos corresponden a las autoridades eclesiásticas y administrativas de la intendencia, mientras que el aporte de las familias acomodadas disminuyó relativamente.

Durante los días siguientes, el pedido de los préstamos continuó y el 12 de enero de 1821, las autoridades virreinales lograron reunir la considerable cantidad de 26,000 pesos en préstamo y 700 pesos en donativo, adicionando un total de 26,700 pesos para el auxilio de las tropas realistas. ${ }^{37}$

37. Ibíd., 1821, f. 69. 
El 19 de febrero de 1821, una vez más por la imposición de las autoridades de Lima, los administradores de Huamanga elaboraron una lista de las familias para un préstamo económico y así solventar los gastos de los dos mil soldados realistas que iban a pasar por Huamanga. Fueron registradas 41 personalidades para otorgar 9,000 pesos de acuerdo con sus propiedades y actividades económicas. ${ }^{38}$ Doña Antonia Villaverde, Ignacia Argumedo y don Macario Galindo fueron designados para brindar 1,000 pesos cada uno; cuatro familias la suma de 500 pesos; y otras cuatro el monto mínimo de 25 pesos (Cuadro 6).

Cuadro 6: Relación de los prestamistas, 1821.

\begin{tabular}{|c|c|}
\hline Familias & Monto en pesos \\
\hline Antonia Villaverde & 1.000 \\
\hline Martina Guillén & 100 \\
\hline Tomás Cárdenas & 100 \\
\hline Celedonio Barbarán & 100 \\
\hline Ignacia Argumedo & 1.000 \\
\hline Macario Galindo & 1.000 \\
\hline Eustaquia Nieto & 500 \\
\hline Pablo Medina & 100 \\
\hline Francisco Herrera & 100 \\
\hline Diego Trillo & 500 \\
\hline Fermín Peñalosa & 500 \\
\hline Sebastián Cárdenas & 300 \\
\hline Pablo Cárdenas & 100 \\
\hline Antonio Manzo (Huanta) & 300 \\
\hline Pablo Lazo & 50 \\
\hline Marcos Pantoja & 100 \\
\hline Manuel Sotomayor & 25 \\
\hline Melchor Pavón & 50 \\
\hline Dominga Guillén & 50 \\
\hline Julio González & 200 \\
\hline Juan Tamayo & 100 \\
\hline Basilio González & 25 \\
\hline Jacinto Infanzón & 150 \\
\hline Nicolás Rospillosi & 25 \\
\hline José Hipólito López & 25 \\
\hline Paulino Chávez & 200 \\
\hline Alberto García & 100 \\
\hline \multicolumn{2}{|l|}{ Pedro Coronado y Castro } \\
\hline Cristóbal Choccña & 50 \\
\hline José Eysaguirre & 50 \\
\hline Alejo Pérez & 250 \\
\hline
\end{tabular}

38. ARAY. Intendencia. Leg. 42, cuaderno 59, 1821, fs. 1-1v. 


\begin{tabular}{cc}
\hline Familias & Monto en pesos \\
\hline María Luisa Barrientos & 100 \\
Justo Romero & 50 \\
Miguel Castillo & 50 \\
Gerónima Prado & 50 \\
Mariano Bellido & 200 \\
Capitán Manuel Narváez (Huanta) & 200 \\
Benavides (Huanta) & 500 \\
Luján Gil (Huanta) & 300 \\
E. Callañaupa & 250 \\
Manuel Mallma Hierro de Choccña & 50 \\
\hline Total & 9.000 \\
\hline
\end{tabular}

Fuente. ARAY. Intendencia. Leg. 42, cuaderno 59, 1821, fs. 1-1v.

Las familias nuevamente se negaron a otorgar las sumas indicadas y consideraron que se hallaban cortos de fondos para su préstamo. La señora Luisa Barrientos sostuvo que, tras la muerte de su esposo en la ciudad de Ica y la crisis de su negocio de aguardiente, le era imposible otorgar los 100 pesos asignados. Además, indicó que apenas tenía una casa y huerta de frutales y alfalfa para pagar el censo de la dicha propiedad. Del mismo modo, la señora Antonia Villaverde, comerciante y esposa de Raymundo Enciso, indicó la imposibilidad de brindar los 1.000 pesos y que «apenas había conseguido 100 pesos». Don Alejo Pérez, natural de Huamanga, también se negó a prestar los 250 pesos y declaró donar 50 pesos; la señora Eustaquia Nieto, viuda de don Martín Herrera Hidalgo, administrador de rentas, indicó que no se hallaba en la posibilidad de pagar los 500 pesos asignados debido a que ya no recibía ganancias de su hacienda Viñas, ubicada en Moquegua, por la incomunicación hecha por los rebeldes y por la falta de mulas para el traslado y venta del aguardiente. ${ }^{39}$

Con la agudización de la guerra, las contribuciones se radicalizaron y fueron de carácter obligatorio tanto para los sectores mediados, como para los pobres. En febrero de 1817, el cabildo de Huamanga aprobó el cobro de impuesto a los comerciantes de la siguiente manera: 4 reales a la libra de tabaco; 2 reales a la libra de Copán; 1 peso a la libra de tabaco en polvo; 1 peso a cada botija de aguardiente, vino y vinagre; 1 peso sobre la arroba de aceite; 4 reales al cesto de ají amarillo; 1 real a otras especies de ají; 4 reales a la arroba de pescado seco; 4 reales sobre cada arroba de garbanzo y de arroz y 2 reales a cada arroba de frijoles y pallares. ${ }^{40} \mathrm{Hacia}$ 1819, el cabildo huamanguino agravó impuestos a los cañaverales y el azúcar en el partido de Andahuaylas; burros y llamas en Lucanas y Parinacochas; así también

39. ARAY. Intendencia. Leg. 42 , cuaderno 59, 1821, fs. 6-9.

40. ARAY. Libro de actas del cabildo de Huamanga desde 1817-1822, s/f. 
se asignó un impuesto al ganado vacuno en Vilcas Huamán. En 1822, el cabildo estableció impuesto a los comerciantes de la plaza de Huamanga. ${ }^{41}$

Los españoles, mestizos e indígenas de Huamanga, en los últimos años de la guerra, atravesaron un empobrecimiento generalizado. Antes de la batalla de Ayacucho, en noviembre de 1824, proporcionaron dinero y subsistencia a las fuerzas realistas. En diciembre del mismo año, pasó a ser la despensa inagotable del ejército de Sucre. Entregaron reses y cientos de fanegas de cebada, maíz y papa. Asimismo, dispusieron cordellates y pañetes para la vestimenta de los soldados, camisas, zapatos, fornituras, morriones, morrales y herrajes (Pozo M. J., 1949, pp. 20-21). Soportaron la última fase y decisiva de la guerra independentista.

Por ende, se produjo la paralización de actividades productivas y la migración de las familias más potentadas. Tras la derrota en la batalla de Ayacucho, los últimos españoles que emigraron de Huamanga fueron: Gaspar Carrillo de Albornoz, Vicente Egurola, Raymundo Gómez, Fernando Fernández, Briandes Cabrera, Pedro Zorraquín, Nicolás Olano, Mariano Chaveguren, Vicente Ruiz, Cayetano del Hierro, José del Pozo, Ignacio Alcázar, Francisco Rodríguez, Julián González, el presbítero Justo Gálvez, Miguel Iriarte, Bernardino Cevallos, José Martínez, María del Carmen Ochoa, Ramón Rodríguez, Pedro Romero y Manuel Mariano Pacheco. ${ }^{42}$ Unos dejaron sus tierras alquiladas, otros al cuidado de sus esposas o familiares. Pero, aun así, sufrieron secuestros y usurpaciones de sus bienes por parte de las autoridades republicanas. ${ }^{43}$

Asimismo, los abusos mediante las contribuciones crearon en todos los sectores un rechazo a la guerra, descontento de la administración virreinal y muchas familias preferían el cese urgente de las contiendas y la implantación de un gobierno que brinde la estabilidad.

\section{Reflexiones finales}

El bando realista en Huamanga se caracterizó por su heterogeneidad y estaba conformado por un sector de españoles, mestizos e indígenas establecidos en las diferentes provincias de la intendencia. En su mayoría, ocuparon cargos administrativos, militares y religiosos; dirigían las actividades hacendarias, ganaderas, mineras y comerciales más solventes de la región. Aunque también, otros eran de condición humilde.

41. ARAY. Libro de actas del cabildo de Huamanga desde 1817-1822, s/f.

42. ARAY. Juzgado de Primera Instancia, Leg. 1, 182, f. 6v.

43. Los españoles más afectados con los secuestros de bienes y que después de la Independencia recuperaron sus bienes fueron: don Gaspar de Carrillo de Albornoz, Vicente Ruiz, Marcelo Castro, Raymundo Gómez y Vicente Egurrola (Quichua, 2019, pp. 126-131). 
Cada sector defendió a la administración virreinal dependiendo de sus beneficios y sus proyectos. Pretendían permanecer en las altas esferas administrativas; continuar desarrollando las actividades económicas que brindaban los mejores ingresos; y conservar los privilegios que les brindó la corona.

Los hacendados de los valles de Huamanga, Andahuaylas, Huanta y el norte de Anco, en pleno proceso de la guerra independentista a pesar de los saqueos, cupos de guerra, disminución de la producción y sus ganancias, lucharon por el control y dominio de sus tierras. Un asunto contencioso que continuó en el período republicano. Igualmente, muchos pueblos indígenas defendieron la causa realista por mantener sus posesiones económicos, privilegios dados por el rey y porque algunas autoridades locales establecieron reformas de salud, educación y seguridad.

La intendencia de Huamanga se mantuvo bajo el gobierno virreinal hasta 1824 y destacó por sus aportes económicos, gracias al predominio de las propiedades hacendarias, las actividades ganaderas y comerciales más ostentosas dirigidas por los españoles, mestizos, curas, militares e indígenas.

Con la derrota en la batalla de Ayacucho, las personalidades y familias del bando realista sufrieron la confiscación de sus propiedades, la decadencia comercial y el abandono de la región. 


\section{Referencias bibliográficas}

Bonilla, H. (2001). La oposición de los campesinos indios a la república: Iquicha, 1827. En H. Bonilla, Metáfora y realidad de la Independencia del Perú (pp. 147-168). Lima: IEP.

Eguiguren, L. A. (1912[2013]). La sedición de Huamanga en 1812. Ayacucho y la Independencia. Lima: Luvia Editores-CEHRA-Municipalidad Provincial de CangalloArzobispado Metropolitano de Ayacucho.

Galdo, V. (1992). Ayacucho: conflictos y pobreza. Historia regional (siglos XVI-XVII). Ayacucho: Universidad Nacional de San Cristóbal de Huamanga.

García, U. (2003). La implantación de la viruela en los Andes, la historia de un holocausto. Revista Peruana de Medicina Experimental y Salud Pública, 20(1), 41-50.

Hamnett, B. (2011). Revolución y contrarrevolución en México y el Perú: liberales, realistas y separatistas, 1800-1824. México: FCE.

Husson, P. (1992). De la guerra a la rebelión (Huanta, siglo XIX). Cusco: CBC.

Igue, J. L. (2012). Bandolerismoy etnicidad en las guerras de la independencia: el caso de los morochucos de Cangallo, Ayacucho (1814-1829). En C. N. MC Evoy, En el nudo del imperio. Independencia y demogracia en el poder (pp. 207-228). Lima: IEP-IFEA.

Méndez, C. (2014). La república plebeya. Huanta y la formación del Estado peruano, 1820-1850. Lima: IEP.

O'Higgins, D. (1804). Informe del intendente de Guamanga don Demetrio O'Higgins al ministro de Indias don Miguel Cayetano Soler. En J. J. Ulloa, Noticias secretas de América. Madrid: Ediciones TURNER-Librimundi.

Pereyra, N. (2016). Los campesinos de Huamanga y la rebelión de 1814. En S. O'Phelan, 1814: la junta de gobierno del Cuzco y el sur andino (pp. 339-361). Lima: IFEA-PUCPFundación M. J. Bustamante de la Puente.

Povea, I. (2014). Minería y reformismo borbónico en el Perú. Estado, empresa y trabajadores en Huancavelica, 1784-1814. Lima: IEP-BCRP.

Pozo, M. (1963). Lo que hizo Huamanga por la Independencia. Ayacucho: Imprenta González.

Pozo, M. J. (1949). Páginas de la historia de Huamanga. Ayacucho.

Quichua, D. (2017). Real y Pontificia Universitas Guamangensis Sancti Christhophosi 1677-1886. Lima: UNSCH.

Quichua, D. (2019). La independencia en la región. Huamanga y la Universidad de San Cristóbal (1795-1824). Huamanga: UNSCH.

Rivera, J. (1977). Geografía de la población de Ayacucho. Huamanga: UNSCH. 
Rojas, C. (2016). La rebelión de 1814 en la ciudad de Huamanga. En S. O'Phelan, 1814: la junta de gobierno del Cuzco y el sur andino (pp. 363-384). Lima: IFEA-PUCP-Fundación M. J. Bustamante de la Puente.

Ruiz, L. (1924). Monografía histórico-geográfica del departamento de Ayacucho. Lima: Imprenta Torres Aguirre.

Sala, N. (1989). Revueltas indígenas en el Perú tardocolonial. Barcelona: Universidad de Barcelona.

Sala, N. (2012). Justicia conciliatorio durante el liberalismo hispano en el Perú: el caso de Huamanga. Anuario de Estudios Americanos, 2(69), 423-450.

Sala, N. (2014). Quedarán ya para el polvo y el olvido: las elecciones a diputados a las Cortes españolas en el Perú, 1810-1824. En A. Martínez, La Independencia inconcebible. España y la pérdida del Perú (1820-1824) (pp. 213-286). Lima: Instituto Riva AgüeroPUCP.

Urrutia, J. (2014). Aquí nada ha pasado. Huamanga siglos XVI-XX. Lima: IEP-IFEACOMISEDH.

Zapata, Antonio; Pereyra Nelson y Rolando Rojas. (2010). Historia y cultura de Ayacucho. Lima: IEP-UNICEF-DED.

\section{Documentos}

Archivo Arzobispal de Ayacucho (AAA)

Archivo Regional de Ayacucho (ARAY)

Archivo General de la Nación (AGN-Lima)

Archivo General de Simancas (AGS)

Archivo General de Indias (AGI) 